\title{
Blasts Less than or Equal to 10000/mm3
}

National Cancer Institute

\section{Source}

National Cancer Institute. Blasts Less than or Equal to 10000/mm3. NCI Thesaurus. Code C150456.

A quantitative microscopic finding indicating that immature mononuclear cells are found at less than or equal to 10000 per cubic millimeter field in a sample. 